\title{
Occipital Cranium Bifidum
}

\author{
A. N. GUTHKELCH \\ From the Combined Neurological Service, Hull Royal Infirmary
}

\begin{abstract}
Guthkelch, A. N. (1970). Archives of Disease in Childhood, 45, 104. Occipital cranium bifidum. This paper describes a follow-up of 74 consecutive cases of occipital cranium bifidum born and treated between 1948 and 1965, and the surgical technique used in their repair.

When no hydrocephalus developed, $86 \%$ of the cases of cranial meningocele, but only $40 \%$ of those of encephalocele, showed normal mental development.

Even when hydrocephalus complicating cranium bifidum was controlled surgically, many of the children were mentally and some also physically handicapped. Hydrocephalus was more frequent when the sac had contained brain tissue than in cases of meningocele.

There were certain cases of massive posterior protrusion of brain tissue combined with an abnormally small cranial cavity in which reduction of the cerebral hernia was impossible: they showed no sign of intelligence for so long as they survived. In such circumstances operation is contraindicated.

Associated development anomalies were frequently encountered, the majority of these involving the neuraxis.
\end{abstract}

Despite a recent awakening of interest in the problems of congenital deformity, relatively little has been written about the management and prognosis of cranium bifidum. Early reports were relatively optimistic, Ingraham and Swan (1943) claiming that $25 \%$ of a series which included 63 occipital lesions were normal, while Fisher, Uihlein, and Keith (1952) gave a figure of $44 \%$. But both series included many cases which had been first seen when more than a month old, and this would tend to exclude some of the more severely deformed babies; nor was the prognosis of meningocele considered separately from that of encephalocele. More recently, Barrow and Simpson (1966) studied 11 cases from birth and noted that 4 out of 6 meningoceles, but only 1 out of 5 encephaloceles, were of normal intelligence. Hydrocephalus had required treatment in 3 cases and there was microcephaly in 4.

Lorber (1967) has recently surveyed 55 cases of occipital cranium bifidum born between 1958 and 1963 and mostly first seen when less than a week old. They comprised 10 meningoceles and 45 encephaloceles. All the meningocele children survived operation and 6 were reported to be physically and mentally normal. Of those with

Received 5 May 1969. encephaloceles, however, 25 had died includîng 8 with hydrocephalus and 3 microcephalic amentso Only $4(9 \%)$ were normal, even 2 of these having needed ventriculo-atrial shunts; the remaining 18 survivors were mentally retarded with physical sequelae as well.

The present paper describes the writer's persona $\overline{\bar{\Phi}}$ experience of this condition and his views on manage ment and prognosis.

\section{The Present Series}

Seventy-four cases of occipital cranium bifidum came under the care of the writer at the Royal Mancheste Children's Hospital between 1948 and 1965. All hav's been followed up to 1968 (or earlier death), and the survivors are now between 3 and 20 years old. As in the series of Barrow and Simpson (1966) and Lorbef (1967) there were more females -51 cases $(69 \%) \rightarrow$ than males. The lesions were originally divided int three categories: pure meningoceles, 'glioceles'-that is to say swelling containing mainly CSF but with somer glial elements in their walls, and encephaloceles. It was found, however, that the mortality, complicationst and ultimate intelligence were similar in patients with meningoceles and 'glioceles', so in the tables that follow they are considered together as meningoceles. On the other hand, it later seemed reasonable to distinguish from among the encephaloceles 9 cases of massive brain hernia with microcephaly. In none of these was therø 
any chance of reducing the contents of the sac by operation; all are dead and the few who survived for more than a few weeks proved to be complete aments. The numbers of cases falling into each group, and their mortality, are shown in Table I.

\section{TABLE I}

Mortality of Occipital Cranium Bifidum

\begin{tabular}{l|c|c|c|c}
\hline Meningoceles & Alive & Dead & Total \\
\hline $\begin{array}{c}\text { No hydro- } \\
\text { cephalus } \\
\text { Hydro- } \\
\text { cephalus }\end{array}$ & 27 & $2(7 \%)$ & 29 \\
$\begin{array}{c}\text { Viable encephalo- } \\
\text { celes }\end{array}$ & $\begin{array}{c}\text { No hydro- } \\
\text { cephalus } \\
\text { Hydro- } \\
\text { cephalus }\end{array}$ & 7 & $3(30 \%)$ & 10 \\
$\begin{array}{l}\text { Massive encephaloceles with } \\
\text { microcephaly }\end{array}$ & 0 & $9(100 \%)$ & 9 \\
\hline Total & 47 & 27 & 74 \\
\hline
\end{tabular}

The case material can conveniently be divided by year of birth into 4 groups each covering 5 years (Table II), which are comparable in size, the introduction of the surgical treatment of hydrocephalus by ventriculoatrial drainage having occurred halfway through the period of study-early in 1958. This operation has influenced the survival rates for hydrocephalic cases considerably (Table III), for of those born and treated before 1958 only 1 out of 9 survives, but of those born since then 12 out of 17 survive though only 6 are of normal intelligence.

Associated deformities were found in 11 cases (13\%) and are listed in Table IV. The similarity with Lorber's (1967) findings is striking. In 4 out of his 5 children with other congenital defects, and in 8 of the present series, the neuraxis was involved; in both series there was one case of Klippel-Feil syndrome with an associated congenital heart lesion, and one of cleft palate.

TABLE IV

Deformities Associated with 74 Cases of Occipital Cranium Bifidum

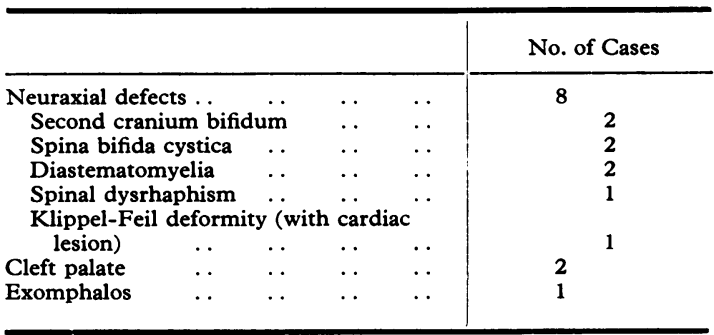

\section{Surgical Management}

Though the various grades of cranium bifidum correspond with those of spina bifida, the surgical problems are different. In spina bifida the commonest, most

TABLE II

Distribution of Case Material with Respect to Date of Birth

\begin{tabular}{|c|c|c|c|c|c|c|}
\hline \multirow{2}{*}{ Year of Birth } & \multicolumn{2}{|c|}{ Meningoceles } & \multicolumn{2}{|c|}{ Viable Encephaloceles } & \multicolumn{2}{|c|}{ No. of Survivors } \\
\hline & Uncomplicated & $\begin{array}{c}\text { With } \\
\text { Hydrocephalus }\end{array}$ & Uncomplicated & $\begin{array}{l}\text { With } \\
\text { Hydrocephalus }\end{array}$ & Actual & Possible \\
\hline $\begin{array}{l}1948-52 \\
1953-57 \\
1958-62 \\
1963-65\end{array}$ & $\begin{array}{ll}8 & (1) \\
7 & \\
6 & (1) \\
8 & \end{array}$ & $\begin{array}{ll}1 & (1) \\
2 & (1) \\
2 & \\
2 & \end{array}$ & $\begin{array}{ll}3 & (1) \\
2 & (1) \\
4 & (1) \\
1 & \end{array}$ & $\begin{array}{ll}2 & (2) \\
4 & (4) \\
8 & (4) \\
5 & (1)\end{array}$ & $\begin{array}{r}9 \\
9 \\
14 \\
15\end{array}$ & $\begin{array}{l}14 \\
15 \\
20 \\
16\end{array}$ \\
\hline Totals & $29 \quad(2)$ & $7 \quad(2)$ & 10 (3) & 19 (11) & 47 & 65 \\
\hline
\end{tabular}

Number of fatal cases in parentheses ( ).

TABLE III

Distribution of Survivors with Respect to Age and Intelligence

\begin{tabular}{|c|c|c|c|c|c|}
\hline \multirow{2}{*}{ Age (yr.) } & \multicolumn{2}{|c|}{ Meningoceles } & \multicolumn{2}{|c|}{ Viable Encephaloceles } & \multirow{2}{*}{ No. of Survivor } \\
\hline & Uncomplicated & $\begin{array}{c}\text { With } \\
\text { Hydrocephalus }\end{array}$ & Uncomplicated & $\begin{array}{c}\text { With } \\
\text { Hydrocephalus }\end{array}$ & \\
\hline $\begin{array}{c}>15 \text { years } \\
11-15 \\
6-10 \\
2-5\end{array}$ & $\begin{array}{ll}7 & (1) \\
7 & \\
5 & \\
8 & (1)\end{array}$ & $\begin{array}{ll}0 & \\
1 & (1) \\
2 & (2) \\
2 & \end{array}$ & $\begin{array}{ll}2 & (1) \\
1 & \\
3 & (1) \\
1 & (1)\end{array}$ & $\begin{array}{ll}0 & \\
0 & \\
4 & (3) \\
4 & (1)\end{array}$ & $\begin{aligned} 9 & (2) \\
9 & (1) \\
14 & (6) \\
15 & (3)\end{aligned}$ \\
\hline Totals & $27 \quad(2)$ & 5 (3) & 7 (3) & 8 (4) & $47 \quad(12)$ \\
\hline
\end{tabular}

( ) Indicates the number of mentally retarded survivors. (IQ/DQ $<70$.) 
serious, and surgically most urgent lesion is myelocele (open myelomeningocele), the closure of which must be achieved within 24 hours, preferably sooner than that, if function in the affected segments of cord is to be preserved. The variety of cranium bifidum which corresponds with this is so-called anencephaly (exencephaly), which is incompatible with life.

In cranial meningocele and encephalocele, as in the closed varieties of spina bifida, surgical intervention is less urgent. In dealing with the present series of cases the general policy was to repair the deformity as soon as the baby was referred, provided that there was no contraindication in the shape of associated infection, undue prematurity, or the like. In one or two cases in which there was established hydrocephalus this complication was treated first.

As time passed, the conviction grew that there are some occipital encephaloceles which are best left alone, namely those in which there is microcephaly with a large posterior protrusion of brain tissue, including not only the contents of the posterior fossa but also the occipital and parts of the parietal lobes of the hemispheres (Fig. 1 and 2). Of 4 surgical explorations of such cases, 2 ended in death when resection of an irreducible cerebral hernia was attempted, while 2 babies in whom the brain was left alone survived a few months but died as aments. The pointer to an unfavourable prognosis is the microcephaly, for sometimes large posterior swellings in cranium bifidum children whose skull size is normal turn out to be simple meningoceles. There are several ways of establishing the nature of the contents of the sac. Preliminary palpation and transillumination of the swelling must not be neglected and information can also be gained from ventriculography (Lorber, 1967) and vertebral arteriography (Barrow and Simpson, 1966). If there is still doubt, diagnostic aspiration can be performed, the

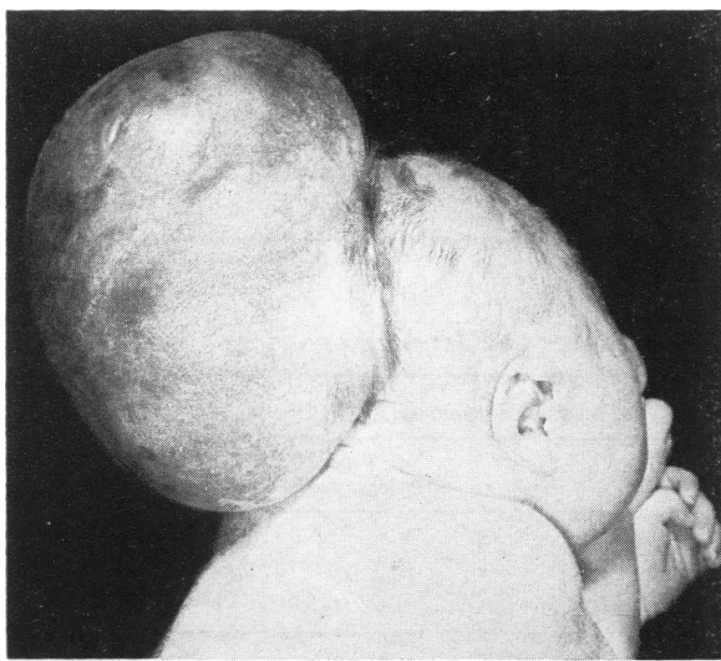

FIG. 1.-A case of massive occipital encephalocele with microcephaly.

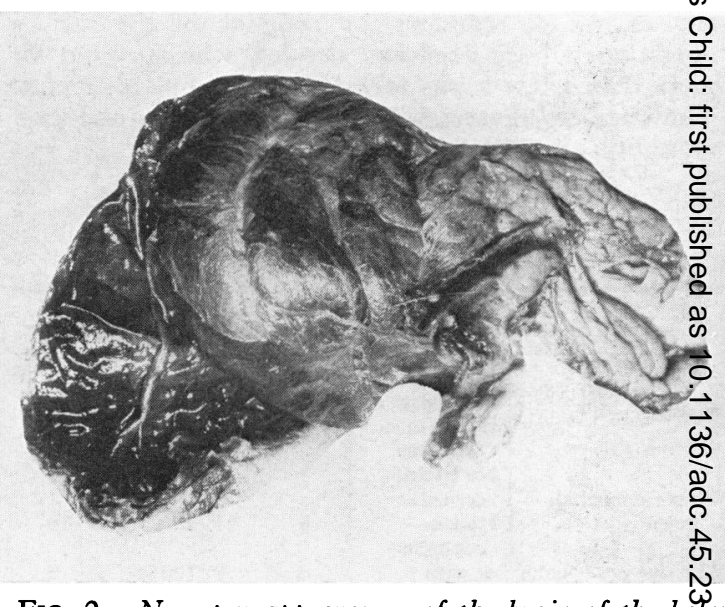

FIG. 2.-Necropsy appearances of the brain of the baby shown in Fig. 1.

demonstration of a large solid mass protruding froำ the skull after the surrounding fluid has been removed being of bad prognosis.

The operation is usually straightforward but one $\$$ two points may be mentioned. Occipital cranizign bifidum is a midline deformity; this implies that neck of the meningeal sac is in close relation dwith either the sagittal sinus, the torcular, or an enlofged occipital sinus, any of which may split to surroumd. It. If such a sinus is inadvertently wounded, msipe haemorrhage or air embolism can occur; it is therefere essential to set up an intravenous infusion before beginning the operation, and to be ready for blopd transfusion.

After the bulk of the sac has been reduced by aspifation the skin is incised, using transverse semi-ellipti商al incisions, and its edges reflected so as to expose the underlying membranes. The whole circumference of the neck of the sac must now be clearly defined and followed down to the skull. If the bony opening is small it should be sufficiently enlarged to ensure good definition of all the structures, otherwise there is a risk of wounding the adjacent venous sinuses, or obstructi them by inclusion in a ligature, with a consequent rise in intracranial pressure. Cerebral tissue should Jif $_{\text {if }}$ possible, be dealt with conservatively, by detaching it from any arachnoid adhesions and replacing it witign the cranial cavity. Small bulbous protrusions Iof obviously abnormal hindbrain may be diverticula of the roof of the IVth ventricle and can sometimes safejty be excised together with the aberrant choroid plexas which they often contain. However, occasionally the sac contains a rather similar knuckle of pinkish anomalous brain tissue which is derived from the meduflia oblongata itself; pressure upon this or the use of diathermy on its surface causes an immediate disturbapce of respiration and any further trauma must be avoided. If there is difficulty in replacing such tissue within posterior fossa, it will be found helpful to tap a ventricte, 
for if up to $25 \mathrm{ml}$. CSF are slowly aspirated, the cerebral hernia will often reduce spontaneously. The redundant meninges are now excised, leaving sufficient tissue at the neck of the sac to allow a secure closure. No attempt need be made to repair the skull defect, but the scalp is sutured in 2 layers, after trimming away redundant skin.

The repair of a cranial meningocele or encephalocele, like the repair of spina bifida, seems sometimes to precipitate an episode of acutely raised intracranial tension with rapid expansion of the head. The underlying cause of the hydrocephalus in these cases is not clear. Its occurrence is prevented neither by avoiding opening a ventricular diverticulum nor by deliberately doing so, neither by excising protruding brain nor by preserving it. Fatal cases in this series have shown at necropsy a variety of malformations, amongst them being aqueduct stenosis, atresia of the foramina of Magendie, and the Arnold-Chiari malformation. Since 1958 all cases in this series in which progressive hydrocephalus developed have been treated by ventriculoatrial drainage, using the Holter valve. Before then, a variety of techniques was used, the commonest being ventriculo-peritoneal anastomosis.

\section{Results}

There were 36 cases of occipital meningocele, 12 of which had sacs containing some glial elements. All were operated upon, but 1 (in which the lesion was associated with a very large teratoma) died on the table. Another infant, who also suffered from a cleft palate and was later found to be severely mentally retarded, has since died at home.

Of the 34 survivors, 27 have never shown any sign of hydrocephalus. 17, of whom 1 also had a cervical meningocele which was repaired simultaneously, are mentally and physically normal; of those now aged 15 years or more, 1 is still at school and likely to obtain a university place, 3 are in regular employment, 1 attends a technical college, and 1 girl is married with a normal baby. 2 survivors are retarded, 1 of them being microcephalic with a DQ of less than 50. 8 survivors though of normal intelligence have some physical handicap, comprising deafness ( 2 cases, 1 with a mild non-paralytic strabismus), paralytic strabismus (1), monoparesis (1), hemiparesis (1-this child also suffered from exomphalos which was successfully repaired by a colleague), spinal dysrhaphism with deformity of one foot (1), diastematomyelia (2:1 with a minimal deformity of one foot, the other with paraparesis).

Seven cases of cranial meningocele developed hydrocephalus of sufficient degree to require operation. 3 of these were treated by ventriculoperitoneal shunts; 2 subsequently died of recurrent intracranial hypertension, while the third survives in a state of severe mental retardation. The other 4 were treated by ventriculo-atrial drainage and their hydrocephalus has been arrested by this means; but 2 are severely retarded and physically handicapped ( 1 also suffering from a cleft palate).

Analysis of the 38 cases of occipital encephalocele reveals a much gloomier picture. The 9 fatal and inoperable cases of massive brain hernia with microcephaly have already been mentioned. Of the others, 10 have shown no sign of hydrocephalus. 3 of these have died, 1 during and 2 within a few months of operation, all being found at necropsy to have multiple severe cerebral malformations. 4 non-hydrocephalic encephalocele children, now aged 16,15, 10, and 7 years, respectively, are normal, but 1 survivor is subnormal (IQ 63) and also suffers from the Klippel-Feil syndrome; the other 2 are grossly retarded and microcephalic.

There were 19 cases of encephalocele with hydrocephalus, of which 11 proved fatal. 5 of these died of their hydrocephalus in the years before ventriculo-atrial drainage was available and 1 died during the attempted removal of the encephalocele following apparent control of the hydrocephalus by ventriculo-mastoidostomy. Of the 5 fatal cases in which a Holter valve had been inserted, 3 died of recurrent intracranial hypertension, 1 of pulmonary embolism, and 1 of subdural haematoma. Among the 8 survivors, all treated by the Holter valve, 3 (now aged 6, 4, and 3 years, respectively) are of low normal intelligence (IQ's 85, 75, and 86) while another who is 5 years old has an IQ of 97 but is handicapped by bilateral cerebellar ataxia. There is 1 subnormal child who is also very ataxic and 3 children are grossly retarded; 3 out of the 4 retarded survivors, but only 1 of the 4 of normal intelligence, have head circumferences which are below normal for age.

\section{Discussion}

The proportion of meningoceles to encephaloceles in an unselected series of cases is still not clear. Fisher et al.'s (1952) series of 9 cranial meningoceles and 48 encephaloceles contained 16 frontal or nasal, 1 temporal, and 6 parietal lesions, and unfortunately the 34 occipital cases were not separately analysed. In Barrow and Simpson's (1966) small series of occipital cases the ratio of meningoceles to encephaloceles was $6: 5$, but in Lorber's (1967) it was 10:45, the writer's being $36: 38$. Selection of cases for referral to hospital may have played a part in determining the differences, for a similar situation has already been noticed 
in respect of spina bifida: the large series of hospitalized cases quoted by Ingraham and Matson (1954) contained meningoceles and myelomeningoceles (including open myeloceles) in the ratio of about 1:2, but Laurence (1964) has shown, and the experience of Sharrard, Zachary, and Lorber (1967) as well as of the writer amply confirms, that the real incidence of simple meningocele in all live-born spina bifida children is less than $10 \%$. Lorber (1967) makes the point that since most of the worst cases of encephalocele die soon after birth, the time of referral to hospital will influence mortality statistics, and this makes it impossible to compare his series with those of Ingraham and Swan (1943) or of Fisher et al. (1952) in respect of mortality or final status. In the present series, as in Lorber's (loc. cit.) most were referred within a week of birth and only 2 when more than 1 year old. Primary microcephaly (as distinct from microcephaly secondary to ventriculo-atrial drainage) was noted in 8 out of $41(19.5 \%)$ of Lorber's children 'who survived long enough to be adequately observed', and in 12 of the present series (16\%). One has the impression that as with spina bifida, the worse forms of the malformation will prove to be commoner than was originally supposed. In considering the wisdom of operating on the most severe cases of cranium bifidum, the ethical problems are mercifully less taxing than in spina bifida where one strives to control grave physical handicap because of the possibility that the crippled body houses a lively intelligence. The writer believes, and Lorber (loc. cit.) strongly implies, that no case of microcephaly with a large posterior protrusion of brain substance can achieve any degree of social independence; it has already been pointed out, however, that the size of the swelling is no guide to the extent of herniation of cerebral tissue.

As to the results of surgical treatment, Lorber (loc. cit) states that, 'the absence of brain tissue in the sac was the single most important favourable prognostic feature for survival ... (while) the $\Omega$ presence of hydrocephalus was an adverse factor'. The present series also shows that the mortality of? encephaloceles is significantly greater than that of $\overrightarrow{\vec{F}}$ cranial meningoceles, but no significant additional death rate was found among those cases of either cranial meningocele or encephalocele who developed $\bar{\omega}$. hydrocephalus provided that ventriculo-atrial drainage was available (Table V).

As to the intelligence of the survivors, microcephaly is an unfavourable prognostic feature, $\vec{O}$ whether it be primary or as a result of a successful operation to correct hydrocephalus. This situation $\vec{\omega}$ is not unique to cranium bifidum; in the writer's experience (unpublished) of surgically treated $\stackrel{\circ}{\Omega}$ hydrocephalics of all types, a greater proportion is of normally intelligent survivors is found among in those whose eventual head size lies within, rather $\omega_{0}^{\omega}$ than above or below, normal limits. It can be $\vec{A}$ calculated from Table III that for all cases of $₫$ cranium bifidum observed in this study the 을 proportion of normally intelligent survivors was significantly less in the hydrocephalic than in the ${ }_{D}$ non-hydrocephalic groups. Taking mortality into 음 account as well, it appears that from a group of children with cranial meningoceles who did not 2 develop hydrocephalus $86 \%$ have survived witi $\overrightarrow{0}$ normal intelligence but only $40 \%$ of those wi encephaloceles. When hydrocephalus was a cons plication the figures were reduced to $29 \%$ and $21 \%$, respectively. From the figures given in Table $I$ it can also be calculated that the incidence of hydrocephalus was significantly higher in the encephaloceles than in the cranial meningoceles $(\mathrm{p}<0.01)$.

My thanks are due to Mrs. M. A. Riley for estimating the Development and Intelligence Quotients, to the many School Medical Officers who helped in tracing the older children, and to Mr. W. A. Pridmore for advice on the presentation of the statistics.

The case of exomphalos mentioned in the text was repaired by Mr. A. Jolleys.

TABLE V

Results of Current Methods of Surgical Treatment

\begin{tabular}{|c|c|c|c|c|c|c|}
\hline & & \multicolumn{2}{|c|}{ Meningoceles } & \multicolumn{2}{|c|}{ Encephaloceles } & \multirow{2}{*}{$\begin{array}{c}\text { Massive Hernia } \\
\text { with Microcephaly }\end{array}$} \\
\hline & & Uncomplicated & $\begin{array}{c}\text { With } \\
\text { Hydrocephalus }\end{array}$ & Uncomplicated & $\begin{array}{c}\text { With } \\
\text { Hydrocephalus* }\end{array}$ & \\
\hline $\begin{array}{l}\text { Total cases } \ldots \\
\text { Alive } \\
\text { Survivors with IQ }\end{array}$ & $\cdots$ & $\begin{array}{l}29 \\
27\end{array}$ & $\begin{array}{l}4 \\
4\end{array}$ & $\begin{array}{c}10 \\
7\end{array}$ & $\begin{array}{r}13 \\
8\end{array}$ & $\begin{array}{l}9 \\
0\end{array}$ \\
\hline$>70 \quad \cdots$ & $\cdots$ & $25 \quad(86 \%)$ & $2(50 \%)$ & $4(40 \%)$ & $4(31 \%)$ & 0 \\
\hline
\end{tabular}

*Subsequent to introduction of ventriculo-atrial drainage. 
REFERENCES

Barrow, N., and Simpson, D. A. (1966). Cranium bifidum. Investigation, prognosis and management. Australian Paediatric fournal, 2, 20.

Fisher, R. G., Uihlein, A., and Keith, H. M. (1952). Spina bifida and cranium bifidum. Proceedings of the Staff Meetings of the Mayo Clinic, 27, 33.

Ingraham, F. D., and Matson, D. D. (1954). Neurosurgery of Infancy and Childhood, p. 6. C. C. Thomas, Springfield, Illinois.

, and Swan, H. (1943). Spina bifida and cranium bifidum. I. A survey of 546 cases. New England Fournal of Medicine, 228, 559.
Laurence, K. M. (1964). The natural history of spina bifida cystica. Archives of Disease in Childhood, 39, 41.

Lorber, J. (1967). The prognosis of occipital encephalocele. Developmental Medicine and Child Neurology, Suppl. 13, 75.

Sharrard, W. J. W., Zachary, R. B., and Lorber, J. (1967). Survival and paralysis in open myelomeningocele. Developmental Medicine and Child Neurology, Suppl. 13, 35.

Correspondence to Mr. A. N. Guthkelch, Combined Neurological Service, Hull Royal Infirmary, Hull. 